\title{
CONTRIBUCION AL ESTUDIO DE ALGUNAS ESPECIES DE ASPRERGILLI AISLADAS EN LA REPUBLICA MEXICANA
}

\author{
Ramón Riba y N. Esparza.
}

El estudio de los hongos del género Aspergillus y su designación con este nombre data del siglo XVIII en el que Micheli los describió en 1729 en su obra "Nova Plantarum Genera", úmicamente desde el punto de visía taxonómico; pero no fué sino hasta mediados del siglo XIX cuando se les relacionó con procesos de fermentación y casos patológicos del hombre, animales y vegetales. Además de Pietro Micheli. Fresenius, De Bary y van Thiegem describieron especies estudiadas por ellos. A medida que el tiempo ha pasado, la importancia de los Aspergilli ha ido en aumento, y en la actualidad forman parte preponderante en la producción de algmnas substancies de valor industrial y terapéutico. Como ejemplo está Aspergillus flavus Link, que entre las substancias producidas por la fermentación que provoca en el meclio de cultivo sobre el que sé desarrolla, forna la llamada flavisidina, con nocer antibintico semejante al de la penicilina aunque en menor esaila; la identidad de estas dos substancias no ha sido probada.

Por to que se refiere al aprovechamiento industrial de productos resultantes de la acción de estos mohos sobre el sustrato, podemos citar el caso del ácido cítrico, de cuya producción mundial más o menos el so\% so obtiene por fermuitacion a base te mohos del género Aspergililus 15, 1\%, 19). Además del ác do cítrioo, fo; Aspergilli pro-

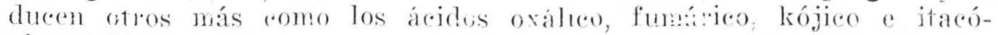
nico (15).

Breve reseña histórica del génzro Aspergillus. - Fl nombre Aspergillus, que cignifiva "cabeza rugosè", como se dijo antes, fué dado a estos mohos por Micholi, cuando antes del decarrollo del mieroscopio y ayndándose de toscas lentes, observó conidióforos y cabezuelas que presentaban una superficie desigual por las largas y numerosas cadenas de conidios formadas en su superficie; posteriormente Persoon (17?0) incluyó a los Aspergilli en el grupo que él denominaba "monilias" basándose en la formación de conidios en cadenas. Link, en 1son, rechazó tal denominación y volvió al nombre propnesto por Miche- 
li, especificando que las cadenas de esporas bien podían tener su origen en una cabezuela.

Todavía en el siglo XIX las formas ascospóricas se eonsideraban como organismos distintos a los Aspergilli, clas ficándose bajo el nombre genérico de Eurotium: ". . a simple vista aparece como una multitud de pequeños cuerpos esféricos amarillentos del tamaño de cabezas de alfiler, descansando sobre filamentos que forman una especie de telaraña a su alrededor. Observándolos con mayor aumento, la su. perficie de los conceptáculos se ve reticulada. En su interior se ven las esporas desnudas, aunque contenidas en ascas. Se ha considerado probable, aunque no se ha demostrado totalmente, que este hongo es una condición ascígena de un moho muy común (Aspergillus)" (De Bary, 1854).

Después, en 1884, Sicard, en su "Histoire Naturelle des Champignons comestibles et Vénenewix", hace referencia a un trabajo de Antón de Bary, en el que explica que los hongos del grupo de los Artrosporados, pueden tomar distintos aspectos a través de su desarrollo. Por la observación hecha del desarrollo de un moho encontrado por De Bary sobre las frutas en conserva llamado Aspergillus glaucus, describe en su trabajo la formación de los cuerpecillos esfériens amarillentos considerados hasta entonces como Eurotium herbariorum.

En resumen, al género Aspergillus se le han dado, a través de casi doscientos años en que se ha acumulado una gran cantidad de literatura sobre él, los siguientes nombres, que deste luego, y atendiendo a las reglas de nomenclatura botánica han pasado a sinonimia: Eurotium (Link, 1854); Sterigmatocystis (Cramer, 1859); Fuaspergillus (Ludwig, 1892); Aspergillopsis (Spegazzini, 1911), y Diplcstephanus (Langeron, 1922).

Caracterización del género Aspergilius. - Los hongos del género Aspergillus, junto con otros como Rhizopus, Penicillium y Mucor, son comúnmente llamados mohos. Por to que se reficre al género Aspergillus, se puede decir que las especies que comprende son cosmopolitas, pues viven en casi todas las latitudes y altitudes del planeta, además de tener, consecuentemente, un habitat muy amplio. Como la mayor parte de los mohos, se desarrollan principalnente sobre materia orgánica en descomposición, pero se han encontrado, además, pa rasitando diversos animales y vegetales superiores.

Morfología. - Analizando al mieroseopio las colonias de Aspergilli, observamos que en la mayor parte de las especies la zona vegetativa de la colonia está formada por un micelio sumergido del que se desprenden hacia arriba las hifas fructíferas, dando a la superficie de la colonia un aspecto aterciopelado; otras producen una red de hifas aéreas más o menos ramificadas y entrelazadas, de las cuales se desprendén los conidióforos, llamándoseles entonces "flocosas". En oca- 
siones el aspecto superficial de la colonia es importante para la clasificación de algunos grupos. Otro carácter que puede en ocasiones tomarse en cuenta para fines sistemáticos, es la disposición de las áreas fructíferas o conidiales, esto es, zonas o regiones donde se promueve la formación de conidióforos que se disponen ya en círculos concéntricos (A. ochraceus), bien en áreas irregulares, o sólo en los bordes de la colonia.

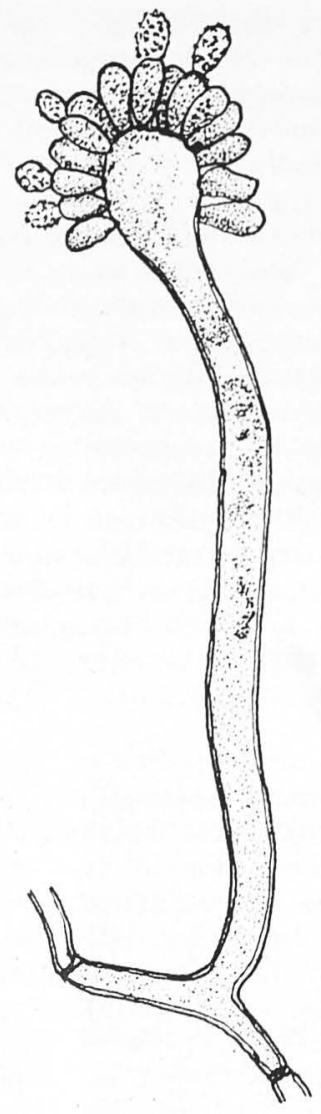

Fig. 1.-Esquema de la disposición de los esterigmas en una serie. (Aspergillus ruber). (25 micras $=16 \mathrm{~mm}$.).

Al hacer un estudio más detallado de la colonia, se distinguen varias partes, que son: el conidióforo, las células basales, la cabeza co- 
nidial, la vesícula, los esterigmas, los conidios, peritecios, ascas, ascosporas y esclerocios. De la superficie de la colonia y de la red de hifas aéreas se formarán las hifas fructíferas, esto es, hifas de las que va a depender la formación de los conidios y que reciben el nombre de conodióforos (figura 1). El origen de los conodióforos está en las células basales, que son células diferenciadas del micelio con pared engrosada, de mayor tamaño que las demás, y que llevan una rama erecta y perpendicular a su eje mayor, que es el conidióforo, el cual en su extremo distal se ensancha y forma la vesícula. Esta prolongación de la célula basal puede ser septada algunas veccs, y aún más, los septos llegan a ser tan apreciables, que se justifica entonces el adjetivo de "articulados" que se les dió a los conidióforos en los primeros trabajos. La pared del conidióforo es más gruesa generalmente hacia la base y se va adelgazando hasta hacerse casi imperceptible a nivel de la vesícula. Esta estructura, que es un ensanchamiento distal del conidióforo, presenta una cierta variedad de formas y puede ser globosa, hemisférica, cupuliforme o clavada, pero cualquiera de ellas presenta una gran superficie para la implantación de los esterigmas. La cavidad interna de la vesícula se continúa con la del resto del conidióforo, y sólo ocasionalmente se encuentra un ligero septo en su base (A. muccroides); no se encuentra con regularidad en ninguna especie.

Ahora bien, un carácter primordial en la clasificación de algunos grupos, es el color y forma de la cabeza conidial o cabezuela, que es la estructura formada por las cadenas o agrunaciones de conidiosporas (fig. 2). Cuando la cabezuela de Aspergillus presenta un color moreno púrpura hasta negro, el moho en cuestión pertenece al grupo $\mathbf{A}$. niger. Las cabezuelas que presentan forma de clava indican que el hongo pertenece al grupo A. clavatus.

Las cabezuelas están constituídas por tres partes, que son la vesícula, los esterigmas y las conidiosporas. Los esterigmas son células a partir de las cuales se forman las conidiosporas y están implantados generalmente en toda la superficie de la vesícula (fig. 3), aunque en algunas especies se disponen en la mitad o dos tercios distales de la vesícula; casi siempre tienen forma clavada y pueden estar dispuestos en una sola serie como en A. niveo-glaucus o en dos series, como en $\mathbf{A}$. versicolor. Cuando se disponen en dos series, en el extremo libre de los esterigmas implantados directamente sobre la vesícula, se desarrollan dos o más esterigmas más pequeños llamados secundarios.

Las conidiosporas se forman en el extremo de los esterigmas por un proceso semejante a una gemación, ya que el núcleo esterigmático se divide por bípartición y uno de los dos núcleos resultantes pasa al cxtremo del esterigma, el que se angosta formando un cuerpecillo esférico o elíptico que es la conidiospora; las sucesivas divisiones de! nú- 
cleo activo del esterigma dan por resultado la formación de una cadena de conidiosporas, en ocasiones con cientos de ellas, capaz cada una de propagar la especie. Las conidiosporas son de origen asexual; tienen entre la membrana externa y la interna substancias colorantes que son las que le dan el color superficial característico a la colonia por la gran cantidad de conidiosporas formadas. Tienen una gran resistencia y pueden conservar su potencialidad por muchos años, aunque algunas especies son extremadamente delicadas y se destruyen con rapidez.

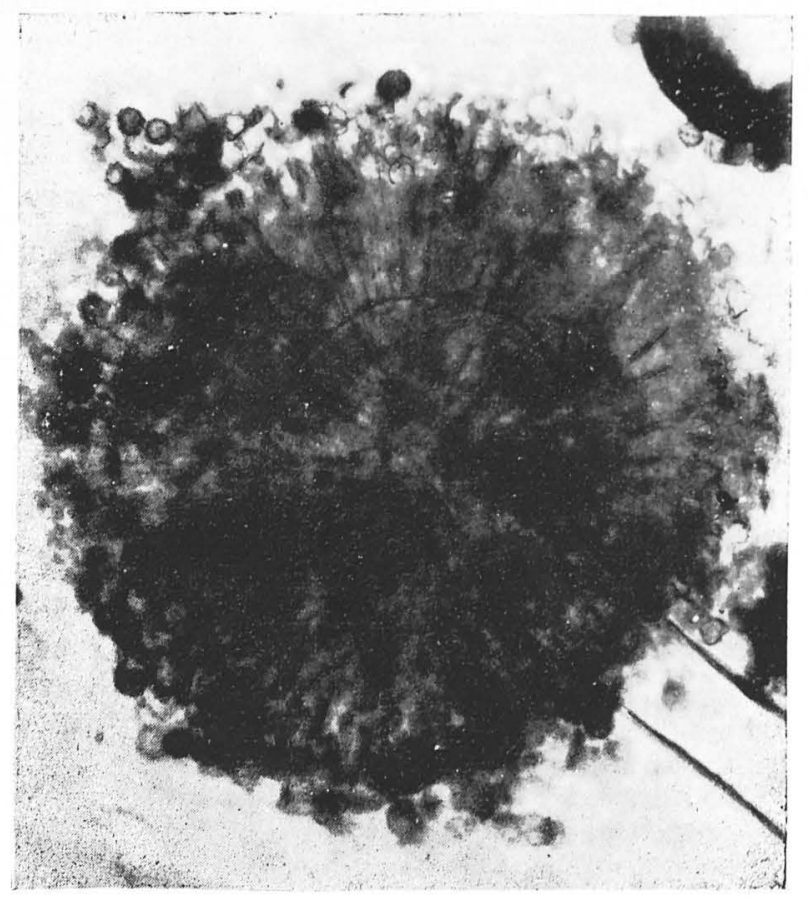

Fig. 2.-Cabezuela madura de Aspergillus fonsecaeus $(320 \times)$

La vesícula es un ensanchamiento del extremo distal del coniclióforo y forma la base de la cabeza conidial; en toda su superficie o sólo en parte de ella, se implantan los esterigmas de los que ya se ha hablado. Los peritecios (fig. 4) constituyen los órganos de reproducción sexual del hongo, y se forman como cuerpos globosos de dimensión variable (90 a 300 micras de diámetro) sobre la superficie del 
sustrato, y quedan flojamente enredados en la hifas del micelio. Estos órganos se presentan con regularidad en especies de los grupos A. glaucus y A. fischeri. En su interior se desarrollan las ascosporas (fig. 5), que tienen la forma de dos valvas simétricas, asumiendo forma lenticular con un surco más o menos acentuado en la zona ecuatorial. Cuando la ascospora germina, las dos valvas se abren y permiten entonces el desarrollo de la hifa, a partir de la cual se formará un nuevo micelio.

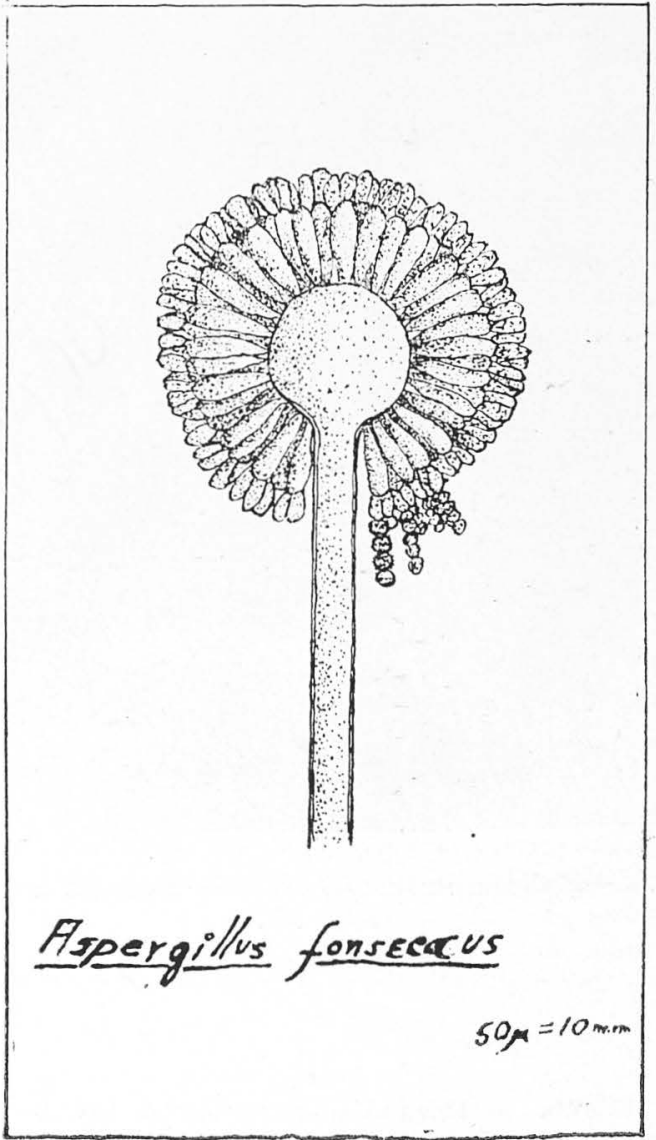

Fig. 3.--Esquema de la disposición de los esteriginas en dos series. (Aspergillus fonsecaeus). $(50$ micras $=10 \mathrm{~mm}$.). 
Por último, los esclerocios son masas compactas con color y estructura características de las especies que los presentan. Están formados por células parenquimatosas de pared muy gruesa y no se conoce su significado genético. Se desarrollan regularmente en especies de los grupos $\mathbf{A}$. candidus, $\mathbf{A}$. oryzae y $\mathbf{A}$. niger.

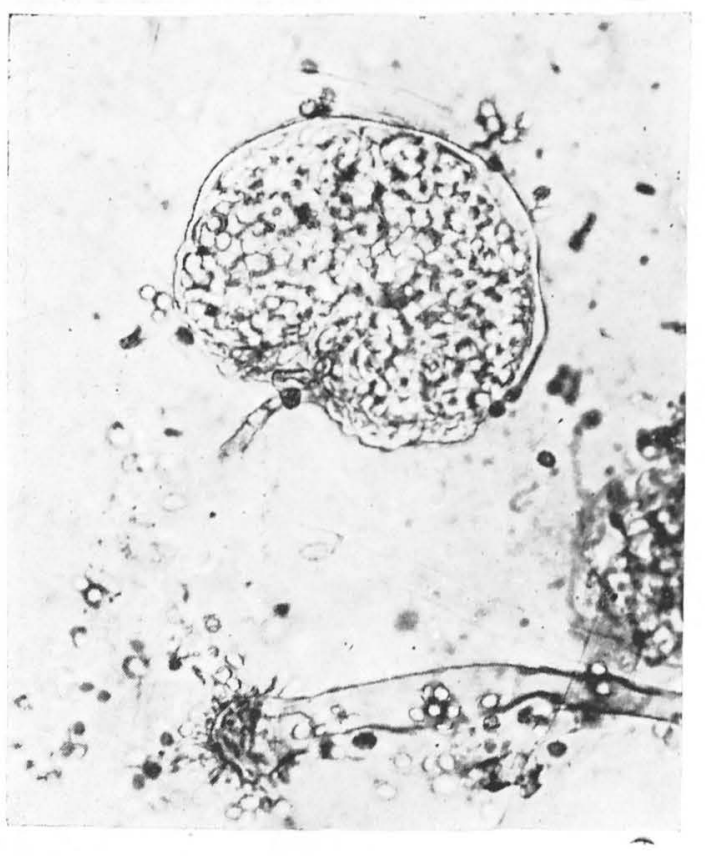

Fig. 4.-Peritecio mostrando ascas de Aspergillus ruber. $(320 \times)$

Medios de cultivo. - Para el desarrollo de las cepas puras se utilizaron dos medios sólidos de cultivo, Saboureaud-Dextrosa y CzapekAgar, habiéndose hecho las observaciones comparativas en cepas desarrolladas sobre este último, cuya composición es la siguiente: 


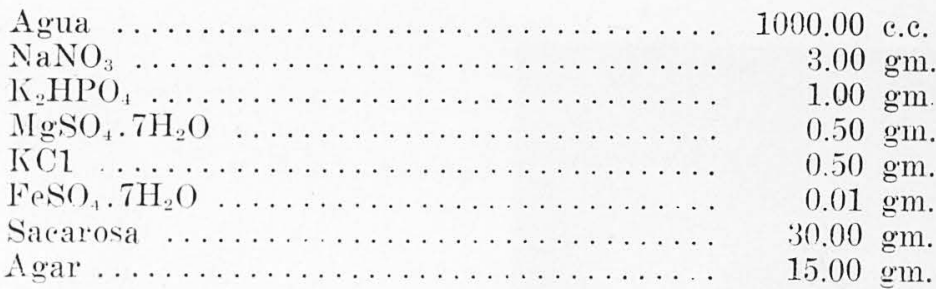

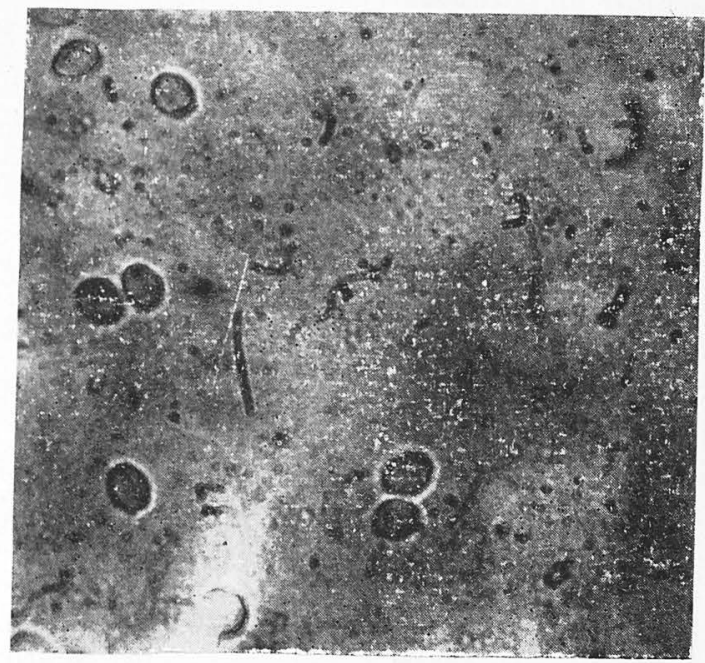

Fig. 5.-Ascoporas de Aspergillus ruber.

$(800 \times)$

La preparación se hace de la siguiente manera: en el agua se disuelven las cantidades correspondientes a las sustancias indicadas; el agua se coloca en un matraz y éste en baño maría, agitando constantemente hasta que se observe la disolución completa de las substancias, principalmente de las partículas de agar, pues de otra manera, al solidificarse el medio habría formación de grumos. Una vez disuelto el medio de cultivo, antes que enfríe y solidifique, se vacía en tubos de ensaye de $150 \mathrm{~mm}$. x $15 \mathrm{~mm}$. Si se van a hacer los eultivos en tubo se vaciarán en éstos de 4 a 5 e.c. del medio. Si los cultivos se desean hacer en cajas de Petri, se llenan los tubos hasta unos 3 a $4 \mathrm{~cm}$. del borde, calculando a razón de dos tubos para cada caja de Petri; no se vacía directamente sobre las cajas, porque la esterilización se hace más fácil en tubos. 

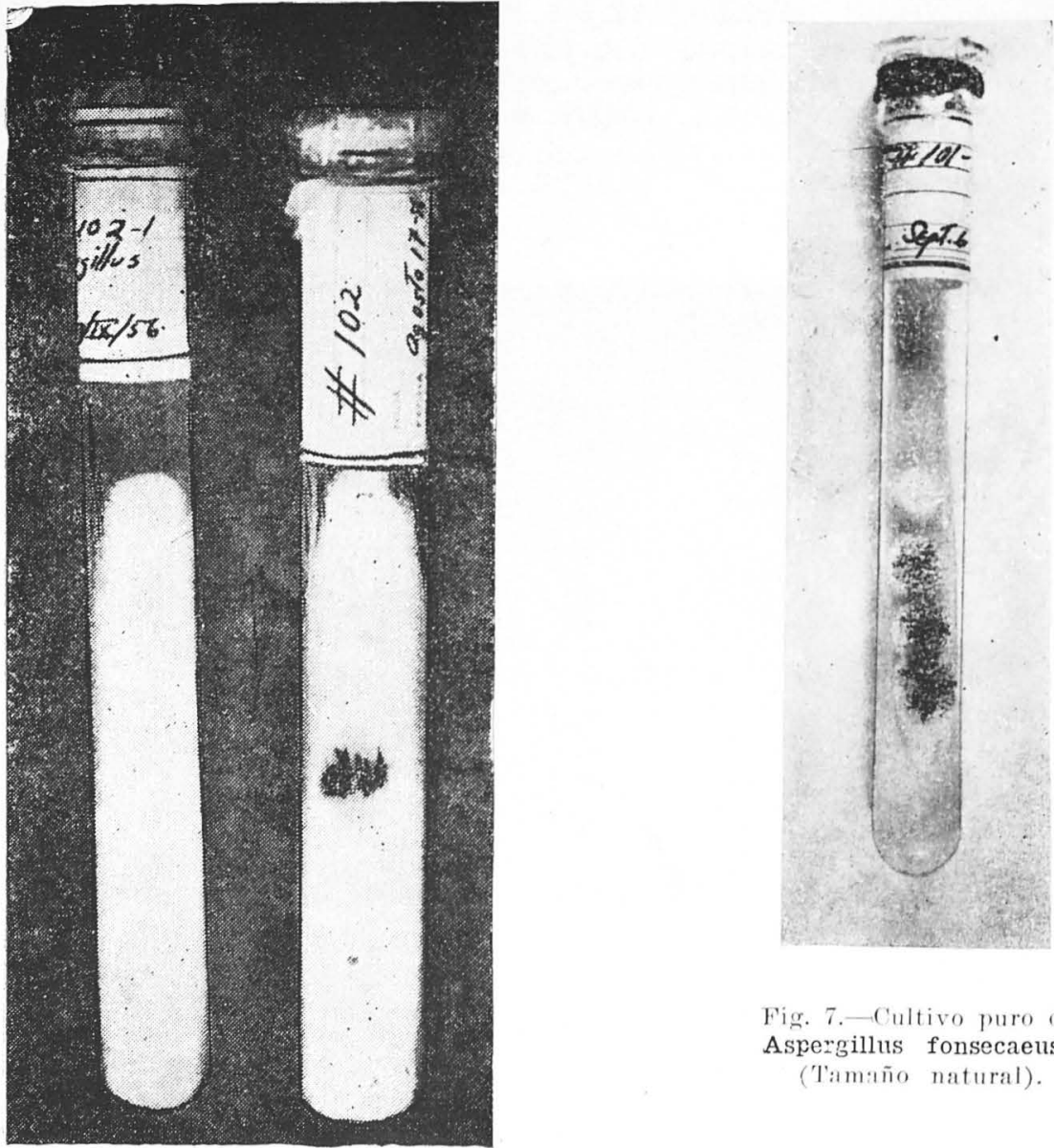

Fig. 7.-Cultivo puro de Aspergillus fonsecaeus.

('l'amaño natural).

Fig. 6.-Cultivos contaminados de Aspergillus fonsecaeus (tamaño natural).

Obtención, purificación y aislamiento de las cepas estudiadas. Para obtener una cepa pura de cualquier especie de Aspergillus se deben seguir ciertos pasos necesarios para su separación, ya que pueden estar contaminadas con bacterias, levaduras y aun con otras especies de mohos en su sustrato natural, lo que puede hacer que presenten 
cambios durante su desarrollo, Jos que se hacen presentes por un encubrimiento del moho provocado por los agentes contaminadores, 0 una alteración consistente en una formación muy abundante de micelio regetativo, sin ninguna traza de formación de conidióforos (figs. 6 y 7 ), y por lo tanto, de conidiosporas, haciendo entonces imposible la identificación de las especies. El método seguido para la purificación de las cepas consistió en la dilución de esporas en ag'ua esterilizada, seguida de una inoculación múltiple en caja de Petri. El material de observación e identificación se cultivó en tubos de ensaye mediante una inoculación en estría. y para detalles macroscópicos de las colonias se cultivaron éstas en cajas de Petri mediante una inoculación central para cbtener una colonia gigante.

Para la obtención de las cepas nuras se partió del sustrato natural del moho, excepto en los cultivos Núms. 50 y 60, los cuales en cepas puras aisladas de piñas parasitadas, fueron donadas gentilmente para su estudio por el Dr. Harry S. Schroeder y la Sra. Ma. de los Angeles II. de schroeder.

Las cepas Núms. 10 y 20 fueron obtenidas de un fruto de limón expuesto a la intemperie; la cepa núm. 30, de un coleóptero colectado cerca de Touala, Guerrero; las cepas Núms. 40 y 80 de semillas de trigo parasitadas procedentes del Estado de Sonora, donadas también por los Sros. Schroeder; la cepa Núm. 70 se desarrolló sobre un rizoma de Dioscorea composita colectado en el municipio de Atzala, Tlapacoyan, Veracruz.

Descripción de las especies estudiadas.

Cepas Núms. 10 y 20.

\section{Grupo: Aspergillus niger (14).}

Especie: Aspergillus fonsecaeus Thom y Paper.

Colonias sobre Czapek Agar con un diámetro de 8 a 9 cm. después de 15 días de inerbación, a una temperatura de $25^{\circ}-28^{\circ} \mathrm{C}$. Abundante micelio vegetativo e incoloro; estructuras conidiales abundantes dispuestas en zonas radiadas (fig. 8) ; cabezuelas de color moreno negruzco (Mummy brown, Ridgway XV-17'-m.) ; reverso de la colonia color obscuro después de dos semanas. Cabezas conidiales grandes, globosas (fig. 2), con numerosas cadenas de esporas unidas en grandes masas flojamente dispuestas, con un diámetro variable entre 380 y $600 \mathrm{mi}$ cras. Conidióforos con longitud de 2.5 a $3.5 \mathrm{~mm}$. y 16 a 23 micras de diámetro; paredes de 2 a 2.5 micras de grueso con superficie lisa e incolora, aunque ligeramente morena cerca de la vesícula. Vesículas globosas de 62 a 88 micras de diámetro, con esterigmas en dos series y dis- 


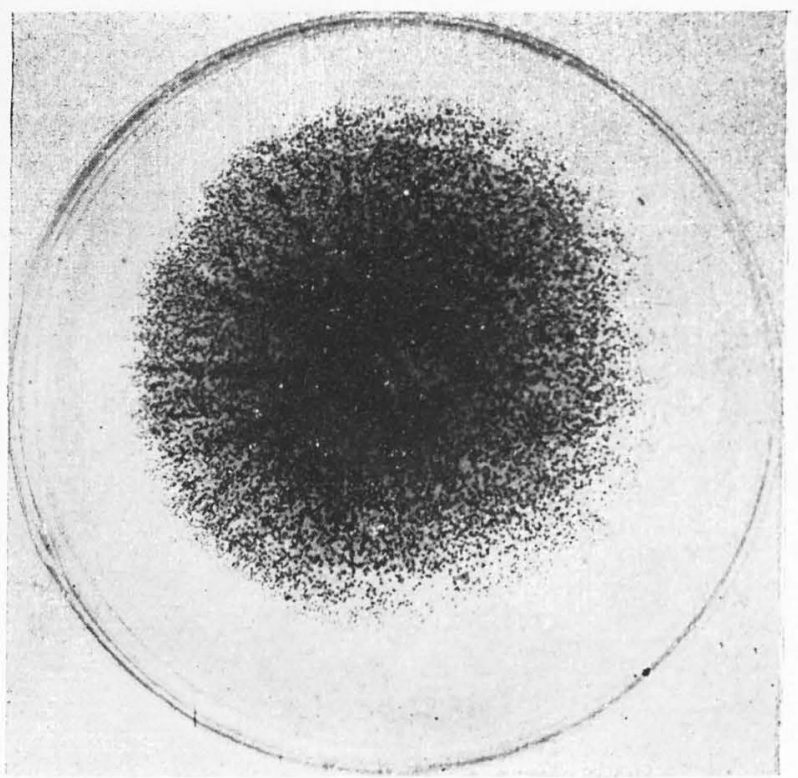

Fig. 8.-Colonia gigante de Aspergillus fonsecaeus (tamaño natural).

puestos en toda la superficie. Esterigmas en dos series color moreno obscuro o claro; esterigmas primarios variables entre 28 a 32 micras por 7 a 9 micras, aunque pueden llegar a medir hasta 56 por 12 micras; esterigmas secundarios de 12 a 16 micras por 3 a 5 micras. Conidios grandes, forma globosa, superficie rugosa, con diámetro de 6 a 8 micras. No hubo formación de peritecios ni esclerocios.

Cepa Núm. 30.

Grupo: Aspergillus glaucus.

Especie: Aspergillus ruber Bremer.

Colonias sobre Czapek Agar con $20 \%$ de sacarosa, incubadas durante 19 días a $24^{\circ} \mathrm{C}$. Son circulares, con bordes ligeramente irregulares; de $7 \mathrm{~cm}$. de diámetro, de color que varía entre el rojo ferruginoso (Ridgway, XIV-9'-i) y rojo marroquí (Moroceo Red; Ridoway, 1-5-k) : peritecios muy abundantes dentro de un denso fieltro de hifas de color rojo; cabezas conidiales globosas sobresaliendo de dicho fieltro de hifas, 
variando de verde grisáceo a verde olivo, más o menos abundantes, enn diámetro de 145 a 165 micras. Conidióforos de 270 a 450 micras de largo con diámetro de 11 a 14 micras (fig. 3) ; pared lisa, ligeramente verdosa, con un grosor de 0.75 a 1 micra. Vesícula subglobosa, de 20 a 25 micras de diámetro; esterigmas en una sola serie y flojamente dis. puestos en la superficie de la vesícula, midiendo de 7 a 8.5 micras por 3 a 4 micras, color verde claro; conidios piriformes o subglobosos, pro. vistos de numerosas espinitas de color verde grisáceo, con dimensiones de 6 a 8 micras por 4 a 5 micras. Peritecios muy abundantes, embebidos en el micelio desarrollado sobre la superficie del medio de cultivo, de color amarillo naranja hasta rojo naranja, subesféricos (fig. 1), de 60 a 110 micras de diámetro; ascas de 11 micras de diámetro; ascosporas lenticulares de 5.5 a 6 micras por 4 a 4.5 micras con una ancha depresión circular poco profunda en la zona ecuatorial de la espora; crestas a menudo indiscernibles; superficie lisa (fig. 2).

Cepas Núms. 40 y 50.

Grupo: Aspergillus niger.

Especie: Aspergillus niger van Thiegem (17).

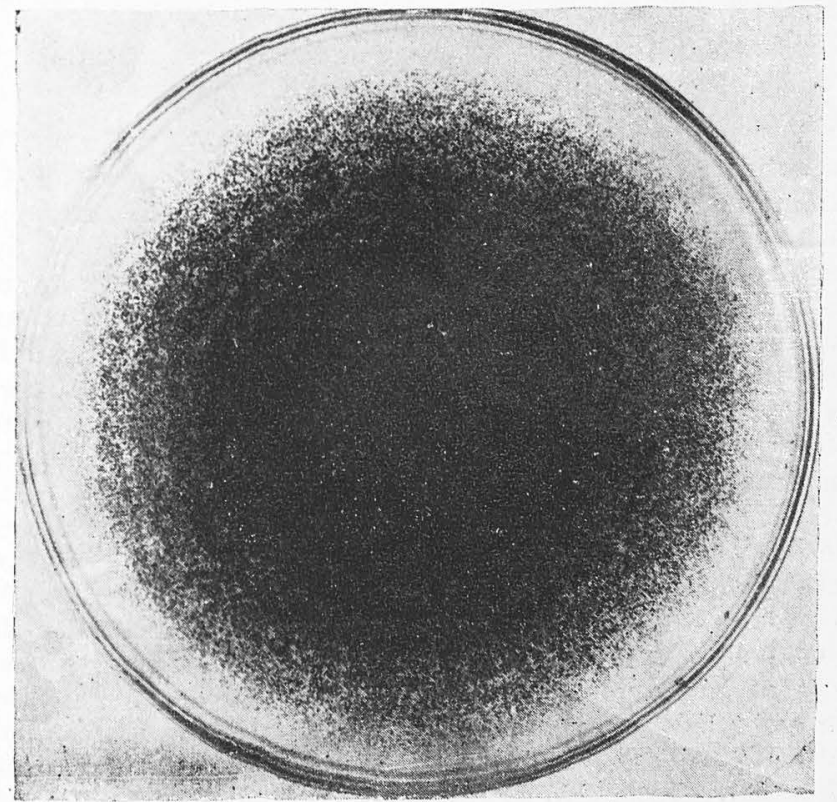

Fig. 9.-Colonia gigante de Aspergillus niger (tamaño natural). 
La cepa Núm. 40 se aisló de semillas de trigo y la Núm. 50 de la superficie de una piña.

Colonias que erecen rápidamente sobre Czapek Agar con sacarosa al 3\% (fig. 10). Tienen abundante micelio incoloro sumergido; hifas aéreas escasas. Areas conidiales concéntricas. Cabezuelas color moreno negruzco, comúnmente globosas y que miden de 240 a 500 micras de diámetro. Conidióforos generalmente incoloros, aunque cerca de la vesícula adquieren un tono amarillento ligeramente moreno, variando su longitud de $0.5 \mathrm{~mm}$. a $1.005 \mathrm{~mm}$. hasta alcanzar en ocasiones 2.280 mm. con un diámetro de 12 a 19 micras. Sus paredes son lisas, con un grosor de 1.5 a 2 micras. Vesículas de forma globosa o subglobosa, de 44 a 64 micras de diámetro, de color moreno amarillento y que presentan una ligera constricción en el logar donde se continúa con el conidióforo (9). Esterigmas en dos series, siendo los primarios abundantes, dispuestos sobre toda la superficie de la vesícula, de color moreno claro; dimensiones: 20 a 35 micras por 5.5 a 7.5 micras; esterigmas secundarios de 5 a 10 micras por 3 a 4 micras. Conidios globosos, color mcreno obscuro, superficie lisa o ligeramente rugosa, con algunas equinu. laciones, y de 3.5 a 4.7 micras de diámetro (19). No se observó formación de peritecios ni de esclerocios.

Cepa Núm. 60.

\section{Grupo: Aspergillus flavus-oryzae.}

Especie: Aspergillus micro-virido-citrinus Const. y Lucet (4).

Colonias sobre Czapek Agar con $3 \%$ de sacarosa y a $24^{\circ}$ C. alcanzando un diámetro de $8.5 \mathrm{~cm}$. a las dos semanas de incubación; presentan abundante micelio sumergido incoloro y superficialmente tienen co.. lor verde cenizo, por la gran cantidad de cabezas conidiales maduras Algunas de ellas son de forma columnar, aunque la mayor parte son globosas; su diámetro es variable entre 100 y 125 micras. Conidióforos de 520 a 840 micras de longitud, con septos transversales algunos de ellos; otros conidióforos pequeños de 100 a 150 micras de largo y unos cuantos esterigmas en la superficie de la vesícula. Su diámetro varía de 9 a 13 micras, aumentando ligeramente en la base de la vesícula. La pared del conidióforo mide de 0.75 a 1.3 micras de grueso; es granular cerca de la vesícula (presenta un aspecto ligeramente rugoso), y lisa en el extremo opuesto; es incolora o ligeramente verde amarillenta en el extremo proximal. La vesícula es semiglobosa, de color verde amarillento con diámetro variable entre 34 y 42 micras. Esterigmas en una sola serie, pocos en número, pero dispuestos en toda la superficie de lia vesícula, de color ligeramente verdoso, variando en tamaño entre 8 y 10 micras por 4 a 6 micras. Conidios color verde claro, de pared delgaca, lisa, de 3.7 a 4.6 micras. No se observó formación de peritecios ni do esclerocios. 
Cepa Núm. 70.

Grupo: Aspergillus flavus-oryzae (11).

Especie: Aspergillus oryzae (Ahlburg) Cohn (3).

Las colonias sobre Czapek Agar son circulares, con bordes ligeramente irregulares y alcanzando un diámetro de 6 a $7 \mathrm{~cm}$. a los 13 días de incubación a $24^{\circ} \mathrm{C}$; t tienen abundante micelio sumergido, con una capa superficial de micelio blanquecino cuando joven; a medida que va madurando se comienzan a formar áreas con diales maduras de color amarillo verdoso primero hasta verde olivo claro en plena madurez. Cazebuelas maduras de forma esférica color verde olivo claro, variando de 250 a 300 micras de diámetro, dándole las cadenas de conidiosporas un aspecto radiado por no estar adheridas entre sí. Conodióforos incoloros de $1.080 \mathrm{~mm}$. a $1.605 \mathrm{~mm}$. de largo y de 11 a 20 micras de diámetro. habiendo alcanzado algunos hasta 32.6 micras. Pared de 0.75 a 1 micra de grueso; algunos de los conidióforos tienen sentos delgados; toda la pared externa de los conidióforos está cubierta de numerosas granulaciones. Vesículas globosas o subglobosas, en algunos casos septadas en la base. de 38 a 60 micras de diámetro. Esteriomas en una serie de 10 a 14 micras por 4 a 5 micras, o en dos series. los primarios de 9.6 a 20 micras por 4.6 a 8 micras, y los secundarios de 7 a 9 micras por 3 a 5 micras. Conidios piriformes de 5 a 6.2 micras nor 3.5 a 4.3 micras, con superficie lisa o ligeramente amarillenta. color verde amarillento.

Esclerocios algo abundantes, duros, blan^os al nrincipio y después de color moreno obscuro de $1 \mathrm{~mm}$. de d'ámetro $(12,13)$.

Cepa Núm. 80.

\section{Grupo: Aspergillus niger (14).}

Especie: Aspergillus awamori Nakazawa (7).

Cultivo en Czapek Agar, durante siete días, a 2.4\% C., con diámetro de $6 \mathrm{~cm}$. y color moreno negruzco; conidióforos de $2.100 \mathrm{~mm}$. a 2.935 $\mathrm{mm}$. de largo por 12 a 18 micras de diámetro; pared lisa, color moreno claro, de 1,6 a 2 micras de grueso. Cabezuelas de color moreno negruzen, globosas, de 390 a 615 micras de diámetro: vesículas globosas, de color moreno claro, de 38 a 56 micras de dámetro. Esterigmas en dos series, los primarios de 8 a 11 micras por 2 a 4 micras, dispuestos en toda la superficie de la vesícula, de color moreno claro. Esterigmas secundarios de 6.8 micras por 2 a 3 micras. Conidiosporas generalmente globosas o en ocasiones elípticas, de 4 a 4.6 micras de diámetro, lisas o ligeramente rugosas. No se observó formación de peritecios ni esclerocios. 
Conciusiones. - De las seis especies de Aspergilli descritas en este trabajo, tres de ellas fueron encontradas viviendo como saprofitas: $\mathbf{A}$. fansecaeus, en un fruto de limón, A. ruber se desarrolló en un coleóptero, cuya clasificación fué imposible por el estado de destrucción en que se encontraba (fig. 9), A. oryzae creció sobre un rizoma de Dioscorea composita a los siete días de colectado. Los otros tres se encontraron viviendo como parásitos: $\mathbf{A}$. niger en semillas de trigo y piñas, $\mathbf{A}$. micro-virido-citrinus en piñas también y, por último, A. awamori sobre semillas de trigo.

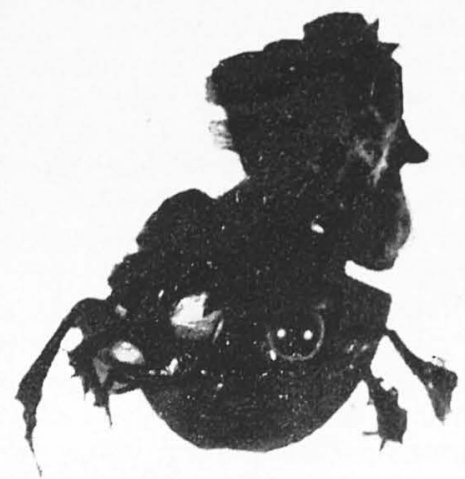

Fig. 10.--Insecto parasitado por Aspergillus ruber. $(2 \times)$

Por lo que se refiere a su patogenicidad en el hombre, se ha reportado A. niger presente en algunos casos de otomicosis $(1,8)$. Las otras especies no han sido reportadas en relcción con alguna micosis del hombre.

\section{REFERENCIAS BIBLIOGRAFICAS}

1.-ANDERSON, C.-Sur un cas d'otomycose a Sterigmatocystis nigra, Arch. Inst. Pasteur Tunis, 15: 93-96, 1925.

2.-BAINIER, G.-Sterigmatocystis fusca Bainier. Bul. Soc. Mycol. France. 27:29, 1880 .

3.-COHN, J.-Jahresb. Schless. Gesell. Vater. Cultur (1183). 61:226. Breslau 1884.

4.-CONSTAN'TIN, J, and LUCET, A.-Ann. Sci. Nat. Bot. TX (2):158, 1905,

5.-CURRIE. J. N.-The citric acid fermentation of A. niger. Jour. Biol. Chem. $31: 15-57,1917$.

6.-KORSCHELT, O. D.-Dingler's Polytechnisches Jour. 230:330, 1878.

7.-NAKAZAWA. R. On the Koji Fungus, Aspergillus awamori. Inst. of Gov't. Research, Formosa, Rept. Vol. I, 1907; Vol. II, 1912. 
8.-SIEBENMANN. F.-Die Fadenpilze Aspergillus flavus, niger, fumigatus; Eurotium repens (und A. glaugus und ihre Beziehung. zar Otomycosis Aspergillina. Zeitschr. Ohrenheilk. 12:124-161. 1883.

9.-SPEGAZZINI, C.-Aspergillopsis nigra (ran Thiegem). Speg. Myc. Arg. V, An. Mus. Nac. Buenos Aires. Ser. 3, 13:434, 1911.

10.-SPIECKERMANN, A. and BREMER, W. Landw. Jahresb. 31:81-128, 1902.

11.-THOM, C. and CHURCH, M. B. Aspergillus flavus, oryzae and associated spemies. Amer. Jour. Bot. 8:103-126, 1921.

12.-THOM, C. and CHURCH, M. B.-The Aspergilli. 112, 1926.

13.-THOM, C. and CURRIE, J. N.-Jour. Agr. Research, 7, 1, 1916.

14.-THOM, A. C. and CURRIE, J. N.--Aspergillus niger group. Jour Agr. Research. $7: 1-15,1916$.

15. THOM, C. and RAPER, K. B.-A Manual of the Aspergilli. Williams \& Wilkins Company, 1945.

16. UNDERKOFLER and HICKEY.-Industrial Fermentations, I; Chemical Publishing Co., Inc., 1954.

17. -VAN THIEGEM, PH.-Aspergillus niger. Ann. Sei. Nat. Bot. s. 5, t. 8:240, 1867.

18. VAN THIEGEM, PH.-Sterigmatocystis nigra. Bul. Soc. Bot. France; 24:102. 103. 1877.

19.-WEHNER, C.-Kleinere mykologische mitteilungen. Zur oxalsauregarung. 3: $102-108 ; 147-153,1897$. 